\title{
O Museu de Arte Moderna do Rio de Janeiro, Maria Martins e a institucionalização da arte moderna no Brasil
}

\author{
Emmanuele Russel" and Gabriela Caspary"I
}

Abstrato: O artigo analisa o período formativo do Museu de Arte Moderna do Rio de Janeiro (1948-1958). Examina documentação da época, explorando as relações políticas, sociais e culturais que envolveram a construção de sua sede própria e a gênese de seu acervo. Nesse quadro, procura pensar sobre a atuação de Maria Martins neste processo institucional.

Palavras-chave: Museu de Arte Moderna do Rio de Janeiro. Sede provisória. Maria Martins. Acervo.

\section{The Museum of Modern Art in Rio de Janeiro, Maria Martins and the institutio- nalization of modern art in Brazil}

\begin{abstract}
The article analyzes the formative period of the Museum of Modern Art in Rio de Janeiro (19481958). It examines documentation from the time, exploring the political, social and cultural relations that involved the construction of its own headquarters and the genesis of its collection. In this context, it tries to think about the presence of Maria Martins in this institutional process.
\end{abstract}

Keywords: Museum of Modern Art of Rio de Janeiro. Provisional headquarters. Maria Martins. Collection.

I Este artigo foi realizado no âmbito do projeto "História da Arte Global" do Programa de Pós-Graduação em História da Arte da UERJ, que conta com apoio financeiro da FAPERJ (Edital n. 12/2019).

II Mestranda em História da Arte pelo Programa de Pós-graduação em História da Arte da Universidade do Estado do Rio de Janeiro. Bacharel em História da Arte pelo Instituto de Artes da UERJ. Discente Universidade do Estado do Rio de Janeiro - Rua São Francisco Xavier, 524 - Maracanã, Rio de Janeiro - RJ, 20943-000. E-mail: e-russel@hotmail. com. ORCID: https://orcid.org/0000-0003-0518-6505. Lattes ID: http://lattes.cnpq.br/7371684492440137. Rio de Janeiro, Brasil.

III Doutoranda em História da Arte pelo Programa de Pós-graduação em História da Arte da Universidade do Estado do Rio de Janeiro (PPGHA - UERJ), bolsista CAPES. Mestre em Arte e Cultura Contemporânea pelo Programa de Pós-graduação em Artes da UERJ (PPGArtes - UERJ). Bacharel em História da Arte pelo Instituto de Artes da UERJ. Discente Universidade do Estado do Rio de Janeiro - Rua São Francisco Xavier, 524 - Maracanã, Rio de Janeiro RJ, 20943-000. E-mail: donasmarcianas@gmail.com. ORCID: https://orcid.org/0000-0001-8708-6086. Lattes ID: http://lattes.cnpq.br/8264347345292304. Rio de Janeiro, Brasil.

IV Tanja Baudoin (1984, Holanda) is a curator living in Brazil since 2015. She obtained a bacheloris and master ss degree in History of Art from the Universiteit van Amsterdam (2008) and a masterss degree in Contemporary Art Studies from the Universidade Federal Fluminense (2019).E-mail: tbaudoin@gmail.com. Rio de Janeiro, Brazil. 
Este trabalho examina a história do Museu de Arte Moderna do Rio de Janeiro (MAM Rio) no período em que esteve instalado no Edifício do Ministério da Educação e Saúde (atual Palácio Capanema). A pesquisa concentrou-se em publicações periódicas produzidas pelo museu a partir de 1952, contendo estatutos, boletins, catálogos de obras, relatórios de atividades entre outros conteúdos relacionados ao funcionamento da instituição nesse momento formador de seu acervo, além de materiais jornalísticos sobre o MAM Rio publicados a partir de 1949. Foi analisada também a participação de Maria Martins neste processo institucional, tendo em vista a relevância da artista para a composição do acervo da instituição.

O presente artigo, assim como $O$ acervo do Museu de Arte Moderna do Rio de Janeiro: a produção experimental e Cildo Meireles, foi desenvolvido a partir

\section{museu de arte moderna do rio de janeiro}

Figura 1 Capa do catálogo da Exposição do Patrimônio do MAM Rio, 1958 . Paginação: Tuni Murtinho. Clichê: Latt Mayer S.A. Fonte: Arquivo MAM Rio. Fotógrafo não identificado

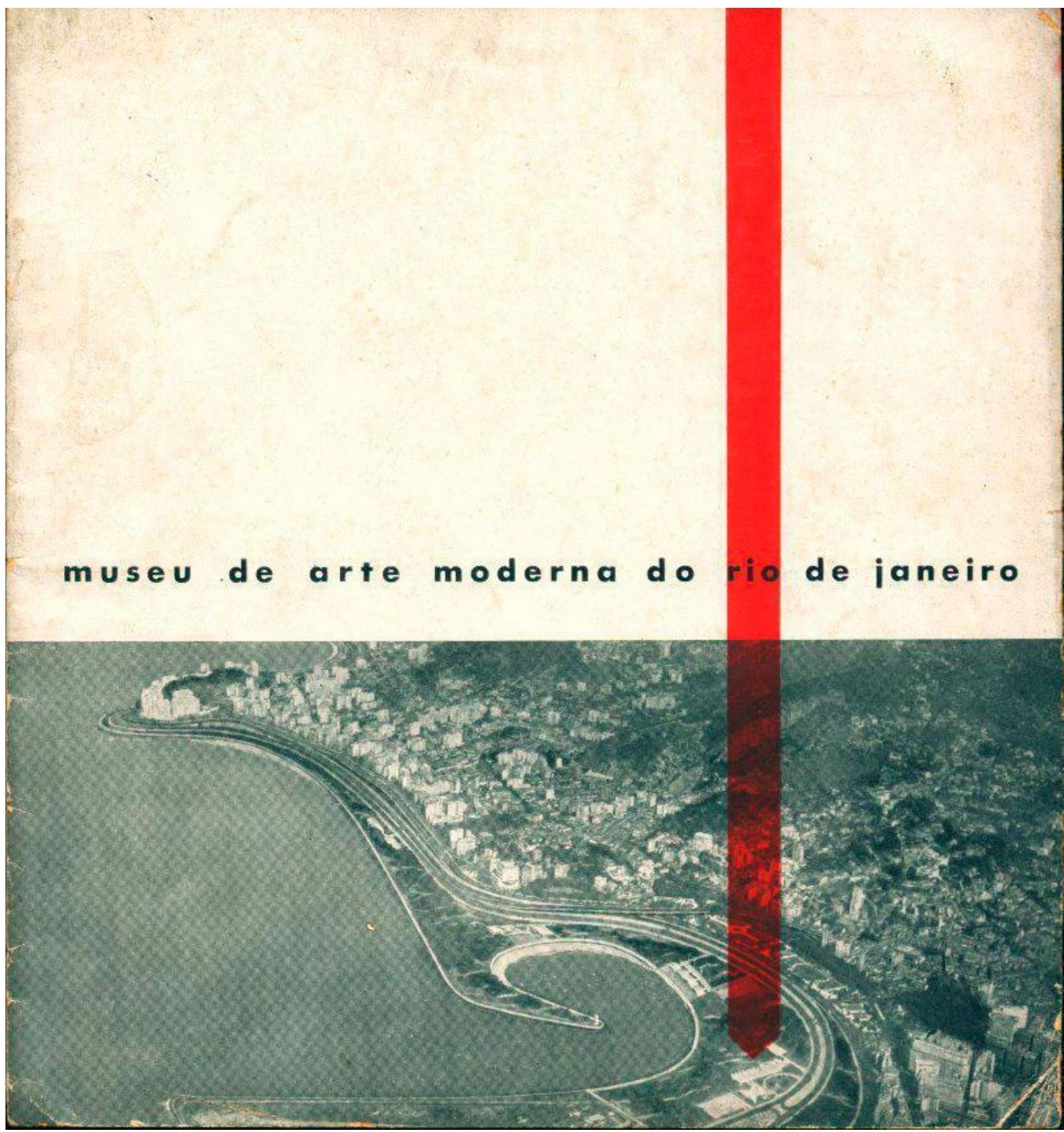


de uma investigação coletiva que reuniu quatro pesquisas sobre o acervo do MAM Rio. O texto elaborado por Daniele Machado e Stefania Paiva analisa a trajetória do museu depois do incêndio de 1978, momento de cisão na relação entre o MAM Rio e as vanguardas, o que deixou uma lacuna histórica na instituição. Entre as iniciativas de reparação relativas à história interrompida em 1978, está o projeto Aquisições Essenciais, um conjunto de aquisições realizadas em 2001, incluindo Marulho, de Cildo Meireles. Dessa forma, a leitura conjunta dos artigos a respeito desses dois momentos da instituição carioca contribui para a formação de um panorama sobre a institucionalização da arte brasileira.

O projeto cultural de institucionalização da arte moderna no Brasil tem como marco a fundação dos museus de arte moderna e da Bienal de São Paulo no fim da década de 1940 e início da década de 1950. É possível identificar neste projeto uma tendência de personalização, como no caso do MAM Rio, frequentemente entendido como uma disputa individual entre Niomar Muniz Sodré e Raymundo Castro Maya. Neste sentido, observar a atuação de Maria Martins pode auxiliar na compreensão de como outros agentes também participaram desse processo e de seu funcionamento em rede. As articulações que envolveram a concepção e a materialização deste projeto moderno se pautaram em figuras proeminentes da dita elite intelectual, política, econômica e cultural brasileira ${ }^{1}$. Esta coletividade, no entanto, não eliminou os problemas inerentes ao patrimonialismo característico da elite brasileira e sua dificuldade em compreender a "distinção fundamental entre os domínios do privado e do público" (HOLANDA, 1995, p. 145).

Apesar do empenho desta elite no projeto, o grande público ainda oferecia resistência em relação à aceitação da arte moderna. Os episódios da rejeição à exposição de Lasar Segall², no Museu Nacional de Belas Artes (MNBA), e do fechamento da exposição do Grupo Guignard ${ }^{3}$, ambos em 1943, são exemplos desta oposição. O gosto do público, de forma geral, estava ligado

1 Dentre elas, destacam-se: Raymundo Castro Maya, Niomar Moniz Sodré, Francisco Matarazzo Sobrinho, Yolanda Penteado, Mário Pedrosa, Assis Chateaubriand, Lúcio Costa, Ivan Serpa, Alberto da Veiga Guignard, Maria Martins, Juscelino Kubitschek, Gustavo Capanema, Oscar Niemeyer, Carlos Drummond de Andrade, Jayme Maurício, Paulo Bittencourt, entre outros.

2 Exposição promovida pelo Ministério da Educação e Saúde no MNBA. Ver: SIQUEIRA, Vera Beatriz. Cálculo da Expressão. Oswaldo Goeldi, Lasar Segall e Iberê Camargo. São Paulo: Imprensa Oficial - SP (IMESP), 2010. (catálogo da exposição). Diário Carioca, Rio de janeiro, p. 6, 22 jul. 1944.

3 Ver: A EXPOSIÇÃO de Guignard na ENBA. A Manhã, Rio de Janeiro, p. 3, 30 out. 1943. 
a padrões tradicionalistas da arte. Sendo assim, para além de contornar as dificuldades estruturais e financeiras relativas à institucionalização da arte, seria necessário o desenvolvimento de um projeto educativo para eliminar o "estado de incultura [que] gerou o academicismo" (BARATA, 1952, p.9). Nesse sentido, a criação de espaços expositivos voltados para a arte moderna se tornava urgente para sua ampla divulgação e formação de público.

A primeira exposição oficial do MAM Rio, denominada Pintura Europeia Contemporânea, foi realizada em 1949 e apresentou obras da chamada Escola de Paris. Esta mostra aconteceu no primeiro endereço do museu, então situado no $16^{\circ}$ andar da sede do Banco Boavista, no Centro do Rio de Janeiro. A mostra reuniu peças de coleções particulares ${ }^{4}$. No mesmo ano, aconteceu a exposição inaugural do MAM SP, intitulada Do Figurativismo ao Abstracionismo.

Segundo Anna Paola Baptista ${ }^{5}$, possivelmente, a escolha da Escola de Paris por parte do MAM Rio teve relação com a influência e predileção do grupo de intelectuais ligados a Castro Maya (tais como Rodrigo Mello Franco de Andrade e Josias Leal), que cedeu parte de suas coleções para esta efeméride. Essas coleções haviam sido formadas a partir de aquisições em leilões fora do Brasil, em mercados de arte com uma estrutura consolidada, diferentemente do incipiente mercado nacional. Essa experiência de atuação no mercado internacional demonstra o entendimento sobre a importância da legitimação e valorização de uma obra de arte por parte desses colecionadores. Nesse sentido, o projeto de institucionalização da arte moderna no Brasil pode ser observado a partir do interesse pela valorização de coleções que eventualmente se apresentassem na vitrine de um museu de arte moderna oficial, como é o caso do MAM Rio.

O engajamento desta elite carioca e paulista no projeto de modernização da sociedade - do qual a institucionalização da arte faz parte - teve influência importante de Nelson Rockefeller e dos modelos aplicados na criação do Museum of Modern Art de Nova lorque (MoMA). A constituição destes espaços institucionais reforçava a potência dos símbolos de um progresso

4 Segundo reportagem do Correio da Manhã, publicada em 21 de janeiro de 1949, p. 12, foram apresentadas obras das seguintes coleções: Coleção Borges da Fonseca, Coleção Niomar Muniz Sodré, Coleção Josias Leão, Coleção Roberto Marinho, Coleção Sra. R. A. Lacroze e Coleção Marques Rabelo. A exposição apresentou duas obras do acervo: uma pintura de Yves Tanguy (doação de Nelson Rockefeller) e um guache sobre papel de Joan Miró (doação de Borges da Fonseca).

5 Chefe da divisão técnica dos Museus Castro Maya (IPHAN). 
necessário para a construção de uma nova sociedade. A rede de relacionamentos que se estabeleceu para a implantação deste projeto no Brasil contou também com a interlocução de Maria Martins, cuja atuação pode ser observada a partir de dois aspectos: sua circulação na cena artística internacional e sua presença no Itamaraty como embaixatriz brasileira nos Estados Unidos (entre 1939 e 1947) e na Europa (de 1931 a 1938 e de 1948 a 1950).

Nesse sentido, a presença de Maria Martins em Nova lorque ${ }^{6}$ reforçava os laços brasileiros com Rockefeller e com o MoMA. Em 1941, o museu norte-americano incorporou ao seu acervo a sua escultura Cristo, adquirida pelo magnata, em exposição na Corcoran Gallery of Art, em Washington. Em 1943, o acervo recebeu, como doação de Maria, a pintura Broadway Boogie Woogie (1942-43), de Piet Mondrian. Durante o período em que viveu em Nova lorque, Maria fez parte do grupo de artistas estabelecidos na cidade, que contava com europeus como André Breton, Michel Tapié, Yves Tanguy e Marcel Duchamp. A presença destes artistas colaborou para que a cidade se tornasse um polo artístico no contexto das migrações decorrentes da segunda grande guerra e com o processo de transferência do centro hegemônico da arte de Paris para os EUA.

Maria Martins retornou ao Brasil em 1950 e, a partir de 1952, entrou para o Conselho Deliberativo do MAM Rio, constando como conselheira até o boletim de 1959, o último analisado por esta pesquisa. Competia ao conselho eleger a direção executiva e deliberar sobre todas as atividades do museu, inclusive sobre a aquisição e alienação de obras ${ }^{8}$. Segundo Ana Arruda Callado", a entrada de Niomar Muniz Sodré na gestão do museu deveu-se à Maria:

Em 1951, a decisão do grupo [de fundadores] era passar a direção do MAM para Maria Martins, principalmente por seus contatos culturais no exterior. Ela, em vez de aceitar,

\footnotetext{
6 Apesar de a embaixada brasileira ser em Washington, Maria Martins manteve ateliê em Nova lorque durante todo o período em que esteve nos EUA (de 1939 a 1947).

7 Esta foi a primeira obra de Mondrian a entrar para a coleção norte-americana e foi adquirida por Maria Martins na exposição conjunta Maria: new sculptures - Mondrian: new paintings, que aconteceu na Valentine Gallery, em Nova Iorque, em 1943.

8 Entre os nomes que se repetem constantemente no Conselho Deliberativo do MAM Rio, nos documentos analisados (1948 e 1959), aparecem: Raymundo Castro Maya, Gustavo Capanema, Rodrigo Mello Franco de Andrade, Juscelino Kubistchek, Roberto Marinho, Carlos Flexa Ribeiro, Aníbal Machado, Francisco Matarazzo Sobrinho, Assis Chateaubriand e Walter Moreira Salles.

9 Autora da biografia da artista, publicada pela editora Gryphus em 2004.
} 
convenceu Raymundo Castro Maya que era melhor entregar o projeto a Niomar e Paulo Bittencourt (CALLADO, 2004, p. 140).

Figura 2 Juscelino Kubistchek, Maria Martins e Niomar Muniz Sodré diante de uma escultura da artista em sua exposição retrospectiva em 1956. Fotografia publicada no Boletim $n^{\circ}$ 15, do MAM Rio, em 1957. Fonte: Arquivo MAM Rio. Fotógrafo desconhecido

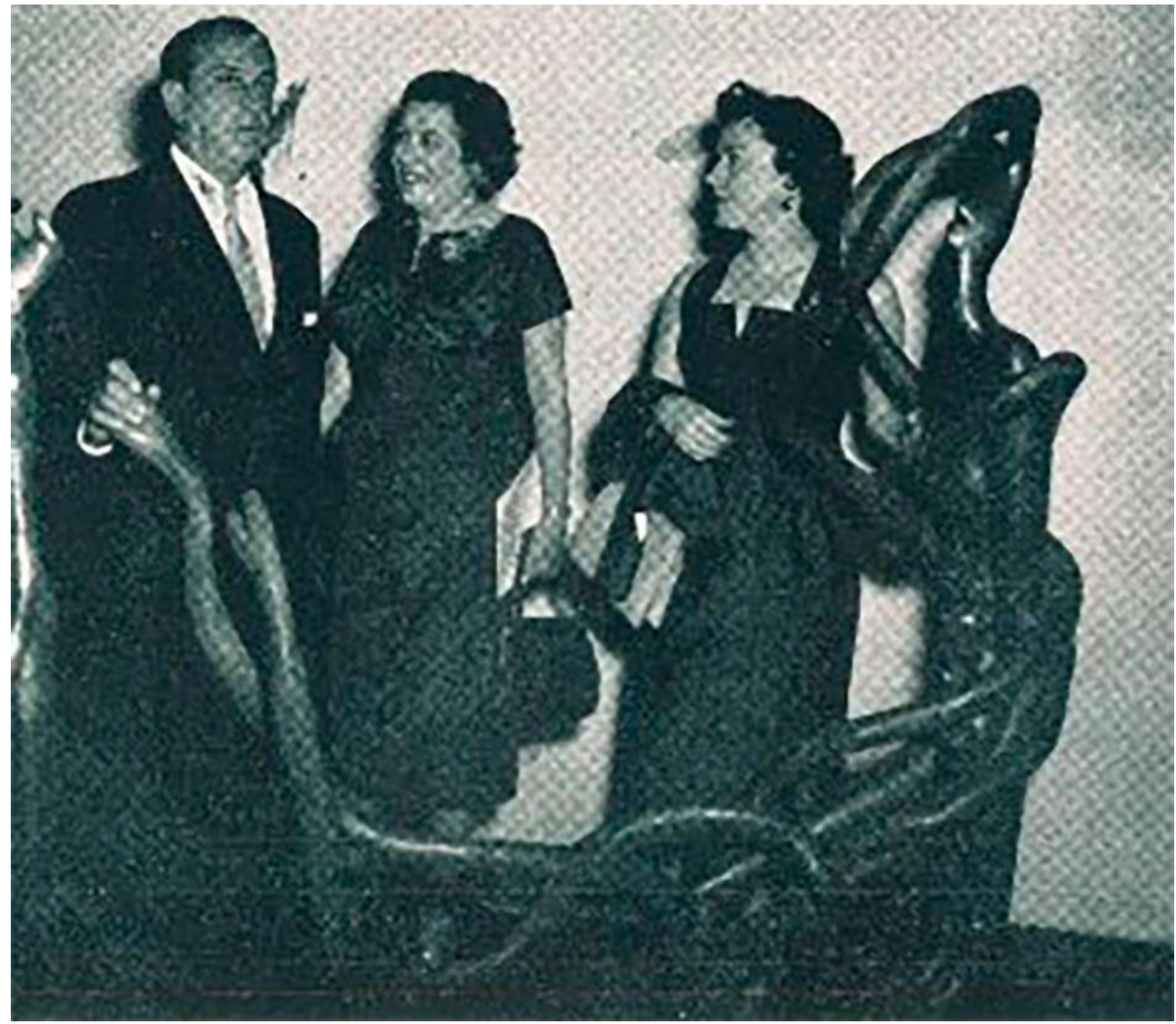

1952 foi um ano de grandes mudanças para o MAM Rio e coincidiu com a entrada de Maria Martins no conselho. Niomar Muniz Sodré assumiu a diretoria executiva e aconteceu a transferência de endereço do Banco Boavista para a sede provisória instalada no Palácio Capanema, na Rua da Imprensa, no Centro do Rio. O museu ocupou os pilotis do edifício, que recebeu um projeto de Oscar Niemeyer, aprovado por Lúcio Costa junto ao $\mathrm{SPHAN}^{10}$, para acomodar provisoriamente o museu. O projeto consistiu no fechamento dos vãos entre os pilotis com uma estrutura de madeira formando o espaço expositivo. O museu ocupou este espaço por seis anos, entre janeiro de 1952 e janeiro de 1958, quando se mudou para o Bloco Escola, primeiro prédio a ser construído na sede própria no Aterro do Flamengo. Em entrevista ao jornal Correio da Manhã, Castro Maya falou sobre a estratégia de ocupação da sede no Palácio Capanema:

10 Serviço do Patrimônio Histórico e Artístico Nacional (SPHAN) foi a primeira denominação do órgão federal de proteção ao patrimônio cultural brasileiro. Atualmente, é denominado Instituto do Patrimônio Histórico e Artístico Nacional (IPHAN). Ver mais em: http://portal.iphan.gov.br/dicionarioPatrimonioCultural/detalhes/61/servico-do-patrimonio-historico-e-artistico-nacional-sphan-1937-1946. 
Será uma sede absolutamente provisória. Por isso, tudo será feito em madeira. Mas permitirá divulgar as atividades do museu, já que é um ponto excelente. E, despertando interesse, conseguiremos sócios e, tendo sócios, iremos para frente (MAYA, 1951, p.5).

A disponibilidade de abertura às transformações artísticas e sociais inerentes ao moderno pode ser entendida como parte do caráter transitório que o MAM Rio estabeleceu na sua primeira década de funcionamento até a mudança para o Aterro do Flamengo. Esta disponibilidade tem relação com a precariedade de sua sede provisória, com as dificuldades para a formação de um acervo e com a instauração de modelos alternativos de museu, diferentes dos tradicionais de arte antiga, que tinham como vocação principal a preservação do passado.

Todo esse esforço, contudo, tem uma finalidade claramente definida: ressalvar a continuidade da cultura num período de grave transição. A relação entre transitoriedade e continuidade é fundamental. A modernidade não se converte em valor cultural e social a não ser quando estabelece essa ambígua relação de continuidade com um passado que pretende negar (SIQUEIRA, 1999, p.142).

O MAM Rio não teve como meta principal a formação de um acervo, "onde a palavra Museu tem outra significação da de somente conservar" (BO BARDI, 1960, p. 130). Seus objetivos estavam mais relacionados a um projeto civilizatório moderno, com um programa educativo, de formação de plateia e alusivo à produção do momento e de artistas jovens, buscando "uma visão panorâmica da arte do nosso tempo" (AQUINO, 1953, p.7). Em consonância com outros empreendimentos deste tipo no mundo - tais como o MoMA, a Galeria Nacional de Arte Moderna de Roma ${ }^{11}$ e o Museu de Arte Moderna de Paris -, a valorização de exposições temporárias, o empréstimo de obras e a legitimação de trabalhos novos foram pontos relevantes no projeto do museu. A defesa de um museu sem acervo como modelo também esteve presente nas argumentações sobre o que seria um museu moderno. O desejo de desenvolver um espaço inovador, que trabalhasse com a arte recente, caracterizou a ambiguidade de um projeto que pretendia participar do desenvolvimento da vanguarda dentro do museu, tendo em vista que a característica primordial de todas as vanguardas é estar a frente do tempo e, por consequência, fora das instituições, sendo incorporada por elas em um momento posterior.

11 De acordo com Vera Beatriz Siqueira, a biblioteca de Castro Maya guardava bibliografia sobre o tema da formação de museus de arte moderna, como o texto de Palma Bucarelli sobre a Galeria Nacional de Arte Moderna de Roma (SIQUEIRA, 1999, p.143). 


\section{A formação do acervo do MAM Rio}

Para a ocasião da inauguração da sede provisória do MAM Rio, no Palácio Capanema, em 1952, foi publicada a primeira lista de obras do acervo, contendo 34 peças ( 21 pinturas a óleo, 1 xilogravura, 8 trabalhos sobre papel - nanquim, aquarela e guache - e 4 esculturas em bronze). Entre os artistas, houve uma predominância de franceses ${ }^{12}, 15$, contra 5 brasileiros ${ }^{13}$.

Dentro da classificação por gêneros presente nos catálogos, a pintura aparece em maior quantidade em todas as listas. Se considerarmos a proporção entre pinturas compradas e doadas, a preferência por artistas franceses irá se manter até a última lista publicada oficialmente pela instituição, em 1966, antes do incêndio de 1978. A questão das doações de obras realizadas por artistas autores foi problematizada pela da crítica nas análises sobre o acervo.

As publicações periódicas produzidas pelo MAM Rio tinham como público alvo seus sócios. Eram tiragens em impressão offset com catálogos de obras $^{14}$, estatutos ${ }^{15}$ e boletins ${ }^{16}$, contendo relatórios de atividades, notícias de imprensa e listagens de sócios. Nos textos publicados, notamos que não houve consenso sobre tendências e influências a serem seguidas para a formação do acervo do Museu. No entanto, as questões relativas a estes critérios estiveram em discussão. Os boletins de 1953 reproduziram críticas de Mário Pedrosa, Antonio Bento e Walter Zanini acerca da constituição do acervo e das coleções que o compunham.

Pedrosa, em sua análise, abordou a questão dos critérios de aquisição, entendendo que, na instituição de um museu, "nenhum ponto é mais decisivo que a formação das coleções” (PEDROSA, 1953, p.13). O crítico falou ainda da importância da opção pela especialização em escolas artísticas devido à impossibilidade de se formar uma coleção totalizante. Sobre a questão das doações,

12 Bores, Couturier, Dubuffet, Duval, Guignebert, Léger, Lhote, Marchant, Mathieu, Metzinger, Patrix, Tanguy, Valtat. O artista Giacometti é classificado na lista como francês e não foi considerado nesta contagem. Léger é o artista com mais obras no acervo, contendo três trabalhos, que foram doados por Nelson Rockefeller, Oscar Niemeyer e Josias Leão.

13 Maria Martins, Portinari, Di Cavalcanti, Guignard e Segall.

14 Esta pesquisa analisou os catálogos publicados em 1952, 1953, 1954, 1956, 1957, 1958 e 1966.

15 Foram consultados para esta pesquisa os estatutos de 1948, 1953 e 1959.

16 Boletins analisados: 1952 ( 1 a 3); 1953 ( 4 a 11); 1954 (12); 1955 (13); 1956 (14); 1957 (15); 1958 (16) e 1959 (17). 
Figura 3 Elaborada pelas auto$\operatorname{ras}(2021)$

\begin{tabular}{|c|c|c|c|}
\hline \multicolumn{4}{|c|}{$\begin{array}{c}\text { Progressão da entrada de pinturas no acervo do MAM Rio } \\
\text { organizadas pela nacionalidade dos artistas }\end{array}$} \\
\hline & 1952 & 1953 & 1966 \\
\hline Alem anha & 0 & 0 & 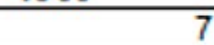 \\
\hline Argentina & 0 & 0 & 9 \\
\hline Áustria & 0 & 0 & 1 \\
\hline Bélgica & 1 & 2 & 3 \\
\hline Bolivia & 0 & 0 & 4 \\
\hline Brasil & 4 & 14 & 126 \\
\hline Chile & 0 & 1 & 3 \\
\hline Chin a & 0 & 0 & 1 \\
\hline Cuba & 0 & 0 & 2 \\
\hline E.U.A & 1 & 8 & 11 \\
\hline Espanha & 1 & 5 & 15 \\
\hline França & 11 & 15 & 39 \\
\hline Grécia & 0 & 0 & 2 \\
\hline $\mathrm{H}$ aiti & 0 & 0 & 2 \\
\hline Inglaterra & 0 & 1 & 3 \\
\hline Israel & 0 & 0 & 1 \\
\hline Itália & 2 & 2 & 31 \\
\hline Iugoslávia & 0 & 0 & 2 \\
\hline Japão & 0 & 0 & 5 \\
\hline México & 0 & 1 & 8 \\
\hline Panamá & 0 & 0 & 1 \\
\hline Paquistão & 0 & 0 & 2 \\
\hline Polônia & 0 & 0 & 1 \\
\hline Portugal & 0 & 0 & 4 \\
\hline Romênia & 0 & 1 & 1 \\
\hline Rússia & 0 & 0 & 4 \\
\hline Suica & 0 & 2 & 3 \\
\hline Tchecoslováquia & 1 & 1 & 3 \\
\hline Uruguai & 0 & 0 & 5 \\
\hline Total & 21 & 53 & 299 \\
\hline
\end{tabular}

enfatizou que elas não poderiam ser incorporadas pelo museu apenas pelo gosto ou pelas amizades e problematizou a doação de obras por parte de autores. Pedrosa referiu-se à coleção de esculturas do MAM Rio como a melhor do Brasil no momento, citando Laurens, Arp, Brancusi, Giacometti e Max Bill, sem mencionar as obras de Maria Martins. No geral, apontou a pintura Cabeça cubista ${ }^{17}$ de Picasso como a melhor obra da coleção. A importância desta pintura será notada também por Antônio Bento, que a elegeu como a obra central no acervo. Cabeça Cubista faz parte do conjunto de obras perdidas no incêndio de 1978.

Antônio Bento, em sua apreciação sobre a formação do acervo, também identificou o problema da gestão de aquisições e doações. Mencionou que 
Figura 4 Fonte: Elaborada pelas autoras (2021)

\begin{tabular}{|c|c|c|c|c|}
\hline \multicolumn{5}{|c|}{$\begin{array}{l}\text { Tipos de aquisição de pinturas por nacionalidade } \\
\text { de acordo com os dados da listagem de } 1966\end{array}$} \\
\hline & Compras & Doação por autores & Doações por terceiros & Sem indicação \\
\hline Alem anha & 5 & 0 & 1 & 1 \\
\hline Argentina & 2 & 3 & 4 & 0 \\
\hline Áustria & 0 & 1 & 0 & 0 \\
\hline Bélgica & 3 & 0 & 0 & 0 \\
\hline Bolivia & 0 & 0 & 3 & 1 \\
\hline Brasil & 11 & 83 & 29 & 2 \\
\hline Chile & 1 & 2 & 0 & 0 \\
\hline China & 1 & 0 & 0 & 0 \\
\hline Cuba & 0 & 0 & 2 & 0 \\
\hline E.U.A. & 7 & 2 & 2 & 0 \\
\hline Espanha & 7 & 4 & 3 & 1 \\
\hline Franca & 21 & 6 & 13 & 0 \\
\hline Grécia & 0 & 2 & 0 & 0 \\
\hline Haiti & 2 & 0 & 0 & 0 \\
\hline In glaterra & 2 & 1 & 0 & 0 \\
\hline Israel & 1 & 0 & 0 & 0 \\
\hline Itália & 10 & 17 & 4 & 0 \\
\hline lugoslávia & 0 & 1 & 1 & 0 \\
\hline Japão & 1 & 2 & 2 & 0 \\
\hline México & 6 & 0 & 2 & 0 \\
\hline Panamá & 0 & 1 & 0 & 0 \\
\hline Paquistão & 0 & 2 & 0 & 0 \\
\hline Polônia & 0 & 0 & 1 & 0 \\
\hline Portugal & 1 & 1 & 2 & 0 \\
\hline Romênia & 1 & 0 & 0 & 0 \\
\hline Rússia & 3 & 0 & 0 & 1 \\
\hline Suica & 3 & 0 & 0 & 0 \\
\hline Tchecos/ováquia & 3 & 0 & 0 & 0 \\
\hline Uruguai & 2 & 0 & 3 & 0 \\
\hline Total & 93 & 128 & 72 & 6 \\
\hline
\end{tabular}

a formação de coleções devia ter em vista "objetivos culturais, pois as coleções de museus diferem substancialmente das coleções de amadores, por mais cultos que estes sejam" e enfatizou a importância de um "programa de aquisições" (BENTO, 1953, p.14).

Walter Zanini, em concordância com Pedrosa e Bento, reconheceu a falta de coesão na seleção de obras da coleção, caracterizada como um "conjunto ainda por demais improvisado" (ZANINI, 1953, p.10) devido à procedência de doações aleatórias provenientes do gosto pessoal de beneméritos.

A aquisição da escultura Mademoiselle Pogany (1920), de Brancusi ${ }^{18}$, foi uma intermediação importante de Maria Martins para a coleção de esculturas do MAM Rio em 1951. Ela narrou o episódio em sua coluna, ${ }^{19}$ no jornal Correio ção do casal Marinho nesta compra intermediada por Maria Martins e Niomar Muniz Sodré.

19 Maria Martins colaborou no jornal Correio da Manhã, entre os anos 1967 e 1968, com uma coluna intitulada Poeira da vida. Neste espaço, ela discorria sobre passagens de sua vida e tecia comentários sociais, do meio artístico ao meio político. 
Figura 5

Pintura Cabeça Cubista de Picasso sendo observada pelo ministro do comércio da Inglaterra. Fotografia publicada no Boletim $\mathrm{n}^{\circ} 17$, do MAM Rio, em 1959. Fonte: Arquivo MAM Rio. Fotógrafo desconhecido

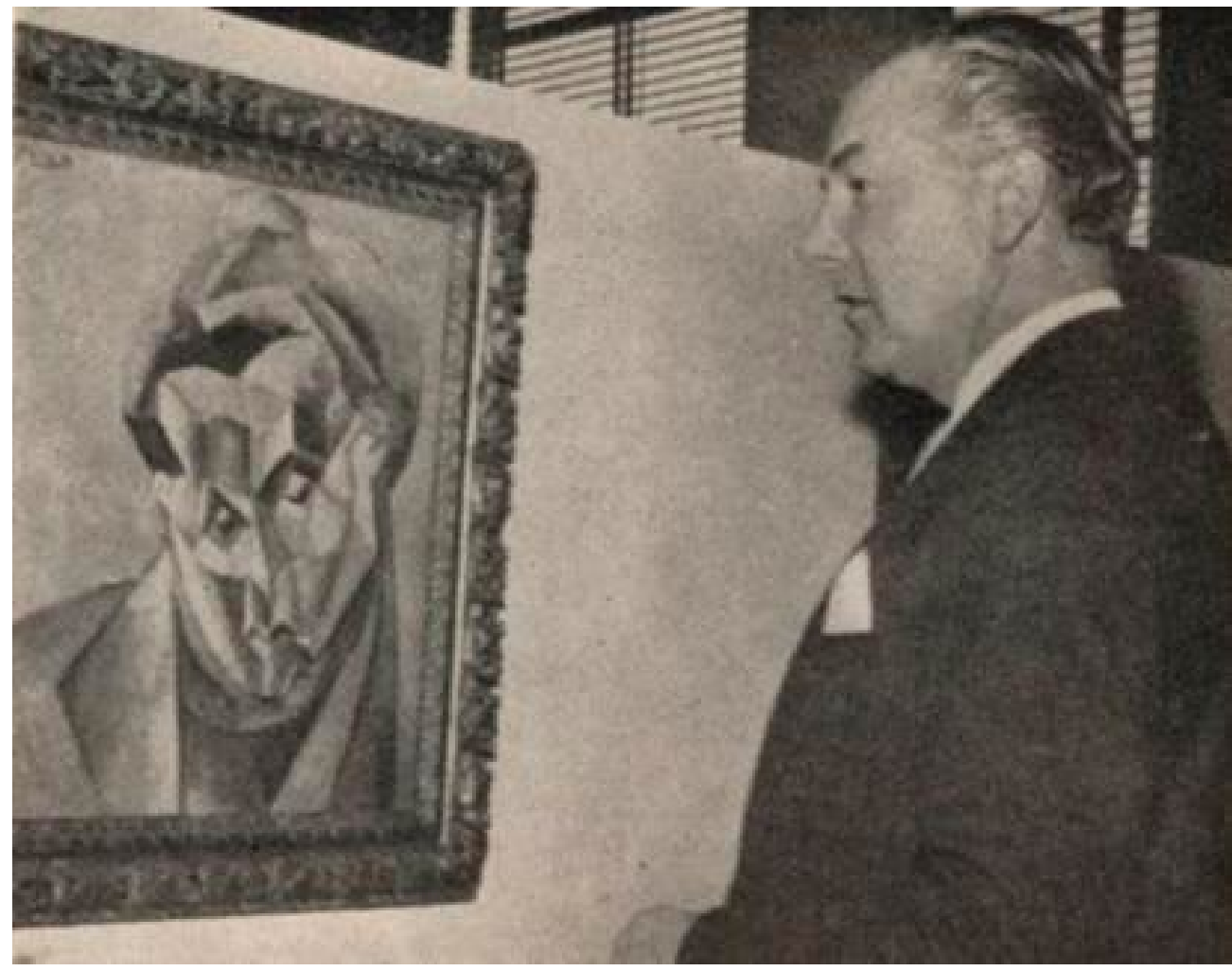

da Manhã, em 1967. O conhecimento deste episódio nos dá a conhecer o ambiente de proximidade e o sistema informal de negociação e aquisição de obras através de Maria Martins.

Em 1951, já então sua velha amiga [de Constantin Brancusi], convidei Niomar Bittencourt para uma visita a seu atelier e para conhecê-lo pessoalmente. [...] Conversamos muito. Niomar contou-lhe de seu sonho: a realização do Museu de Arte Moderna, no Rio, então apenas em um início difícil. Niomar saiu triunfante, levando o retrato de Mademoiselle Pogany, de 1920, uma das obras mais importantes do artista, porque das primeiras realizadas após a transformação de seu estilo com a simplificação das linhas (MARTINS, 1967, p.1).

Entre as galerias de arte que constavam na lista de aquisições desta primeira fase de formação do acervo do MAM Rio, pode-se citar a Sidney Janis Gallery e a Betty Parsons Gallery, ambas em Nova lorque. A primeira funcionou desde 1948 e ficou conhecida por ter agenciado importantes artistas de vanguarda daquela geração, tendo organizado exposições de Marcel Duchamp e Piet Mondrian nas décadas de 1940 e 1950. A aquisição da pintura Cabeça Cubista, de Picasso, foi efetuada nesta galeria em 1952. É possível identificar na correspondência entre Duchamp e Maria Martins troca de informações sobre contatos e exposições em galerias de Paris e Nova lorque. A Betty Parsons Gallery ficou conhecida por lançar e negociar grandes nomes do expressionismo abstrato. A aquisição para o 
acervo do MAM Rio das pinturas $N^{\circ} 4-A$ (1947), de Mark Rothko, e Good Fryday (1951), de Theodoros Stamos, foi realizada nesta galeria em 1952. A presença de Maria Martins na cena artística de Nova lorque deste período é um forte indício de que ela pode ter intermediado estas compras. O fato de Nelson Rockefeller ter doado ao MAM Rio trabalhos de Motherwell, Pollock e Tanguy, que pertenciam ao círculo social de Maria Martins, corrobora a hipótese de que a artista estivesse envolvida na escolha de obras e artistas incorporados pelo museu carioca.

Além da assessoria na intermediação de aquisições, Maria Martins doou para o acervo do MAM Rio uma pintura de Dubuffet ${ }^{20}$, e seu marido, Carlos Martins, doou duas esculturas de Lipchitz ${ }^{21}$. Em 1952, a artista ofereceu duas de suas esculturas à coleção: O Impossível (bronze, 1945) e O oitavo véu (bronze,1949). Atualmente, apenas O Impossível encontra-se na coleção. Esta pesquisa não encontrou dados sobre a alienação de $O$ oitavo véu. As esculturas de Lipchitz e de Brancusi ainda permanecem no acervo, mas a pintura de Dubuffet foi perdida no incêndio de 1978.

Nestes anos iniciais, o MAM Rio publicou apenas duas listas completas com obras do acervo (1952 e 1953). A lista de 1953 indica um aumento significativo na coleção, passando de 34 a 82 obras ( 53 pinturas, 13 esculturas e 16 trabalhos sobre papel - gravura, guache, nanquim). A listagem traz a informação de que 35 obras foram doadas, sendo 17 delas doações dos autores.

Nos anos de 1954, 1956 e 1957, o museu publicou apenas listas parciais da coleção, apresentando as novas obras do acervo. Estas listas correspondem também aos trabalhos apresentados na exposição anual do patrimônio do museu, que acontecia regularmente de janeiro a março. $\mathrm{O}$ espaço expositivo nos pilotis do Ministério da Educação era pequeno, não comportando a apresentação da totalidade do acervo nem a manutenção de sua exibição permanente. Ao observar o padrão de aproximadamente 30 obras nas listas parciais, podemos supor que este era o número de obras que caberiam no espaço.

Como indicou Castro Maya, em sua entrevista ao Correio da Manhã, a afluência de público era uma meta importante do museu. A contagem do público

20 Jean Dubuffet, Retrato de Antonin Artaud, 1947. Doação realizada em 1952.

21 Jacques Lipchitz (Lituânia, 1891 - Itália, 1973) foi professor de Maria Martins na técnica do bronze com a qual ela trabalhou em suas obras. Obras doadas ao acervo do MAM Rio em 1956: Pastorale (bronze, 1933-34) e Enlevement de L'Europe (bronze, 1938). 
Figura 6

Progressão de quan-

tidade de obras do

acervo do MAM Rio organizadas a partir das listas publicadas pelo museu entre 1952 e 1966. Fonte: Elaborado pelas autoras (2021).

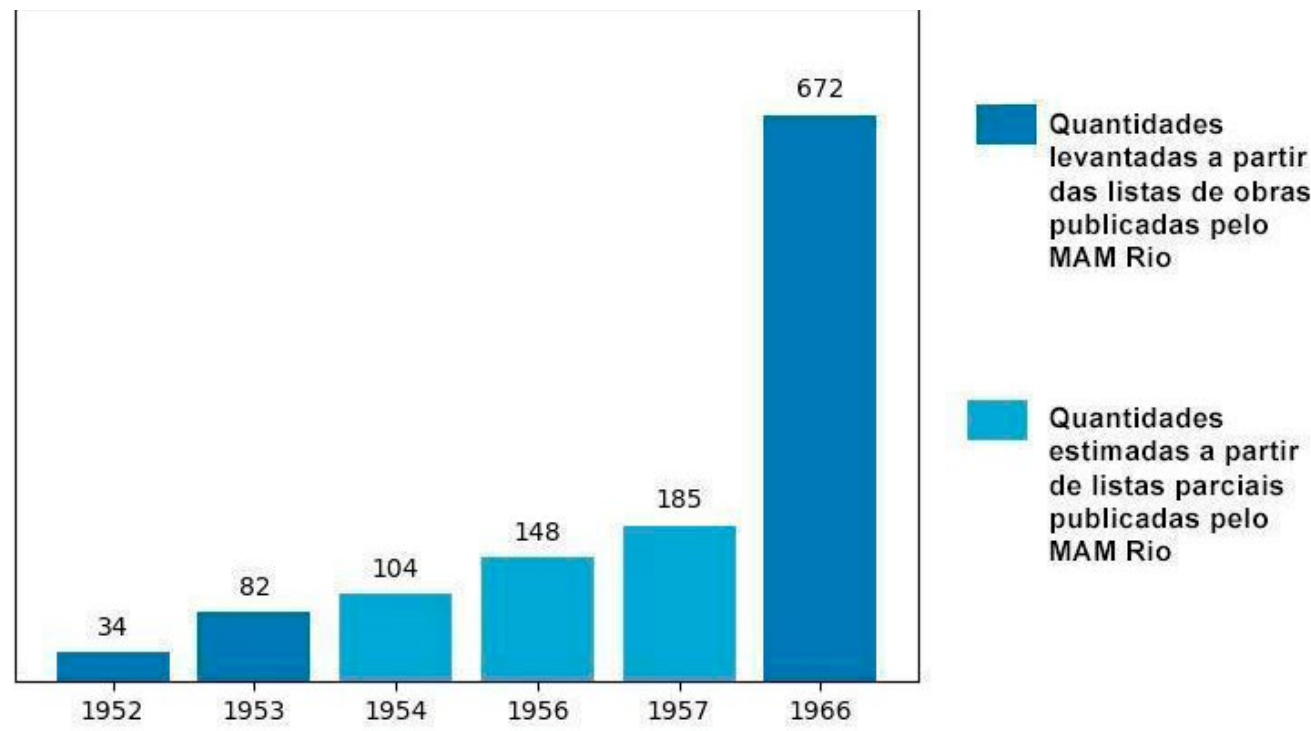

era registrada nos boletins periódicos. O Boletim n 8 , de 1953, apresentava uma notícia de $O$ Globo que anuncia a visita de 73.000 pessoas em 16 meses de funcionamento do museu no Palácio Capanema. O Boletim $n^{\circ} 14$, de 1956, anunciava que, no ano anterior, o museu havia recebido a inscrição de 1.142 novos sócios contribuintes, fechando o número total de 3.159 sócios deste tipo. Na publicação do catálogo da exposição do patrimônio e da inauguração da nova sede, em 1958, foram anunciados 6.000 associados. Neste ano, o museu anunciou a entrada de 5 milhões e 710 mil cruzeiros como renda gerada pelas contribuições de sócios.

Como parte do mesmo projeto institucional moderno, o MAM Rio e a Bienal de São Paulo foram instituições parceiras. Francisco Matarazzo Sobrinho fez parte do conselho deliberativo do MAM Rio desde 1952. A colaboração entre as duas instituições pode ser observada na constituição do acervo do MAM Rio a partir dos prêmios de aquisição oferecidos pelo museu a vendedores da Bienal. A presença de Maria Martins também pode ser observada nesta sinergia. Ela trabalhou como consultora na organização e na seleção de artistas e países da I Bienal, que aconteceu em 1951. Junto com Yolanda

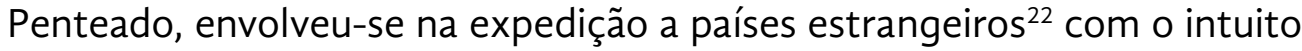
de estabelecer contatos e convites de participação na nova mostra internacional, que teve a Bienal de Veneza como modelo. A primeira exposição do 
Figura 7

Vista do espaço expositivo na sede provisória do MAM Rio na ocasião da realização de uma conferência pública. Fotografia publicada no Boletim $n^{\circ} 15$ do MAM Rio em 1957. Fonte: Arquivo MAM Rio. Fotógrafo desconhecido

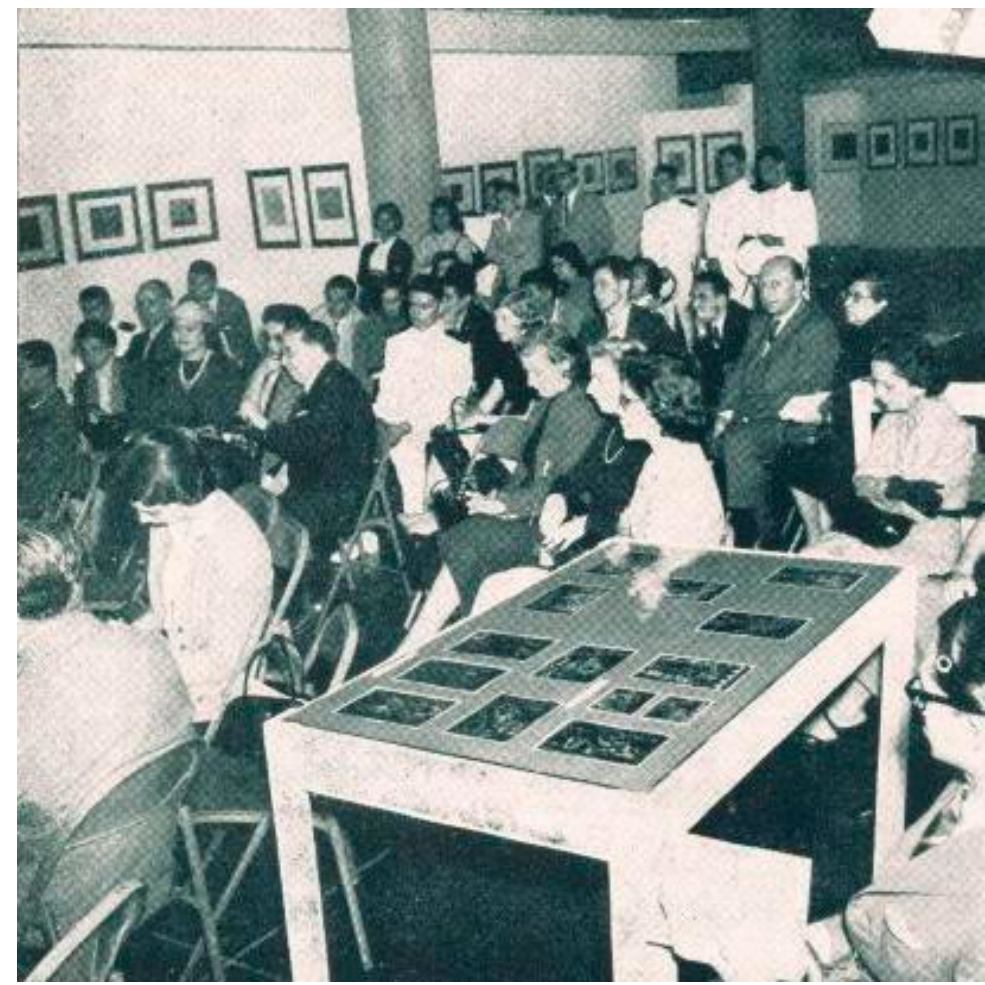

acervo do MAM Rio, em 1952, apresentou também as obras vencedoras da I Bienal e teve grande sucesso de público (18.820 pessoas).

O MAM Rio publicou apenas dois textos críticos no conjunto de listas de obras do acervo. O primeiro foi assinado por Mário Barata para o catálogo de 1952. O segundo, de autoria de Flávio de Aquino, foi publicado no catálogo de 1953. A partir deste ano, os catálogos passaram a ser publicados sem texto. Ambos os textos apresentavam um caráter histórico e didático em relação à arte moderna, deixando clara a dificuldade de constituição de um acervo e justificando dessa forma a falta de coesão da coleção. Barata fez um esforço de elaboração a respeito de qual deveria ser o caráter de um museu de arte moderna enquanto Aquino, mesmo mencionando as dificuldades em se formar um acervo moderno, concentrou-se numa apreciação histórica da arte.

Hoje em dia, mesmo nas coleções permanentes, utiliza-se o rodízio de algumas peças a fim de renovar e variar o interesse da visita. Para esse fim, podem ser usados empréstimos, inclusive de particulares, como ocorre no Museu de Arte Moderna de Paris. Além disso, pode-se notar que certos pequenos museus já são organizados sem exposições permanentes. Em relação aos museus de arte moderna, as exposições temporárias constituem o instrumento específico de trabalho vivo, pois há grande diversidade e quantidade de produção, sem que se possa saber, com certeza absoluta, tudo que se deve comprar (BARATA, 1952, p. 13). 
Figura 8

Frequência de público nas exposições do acervo permanente na sede provisória do MAM Rio entre 1952 e 1957. Gráfico montado a partir do número de visitantes publicado nos boletins do MAM Rio. Fonte: Elaborado pelas autoras (2021).

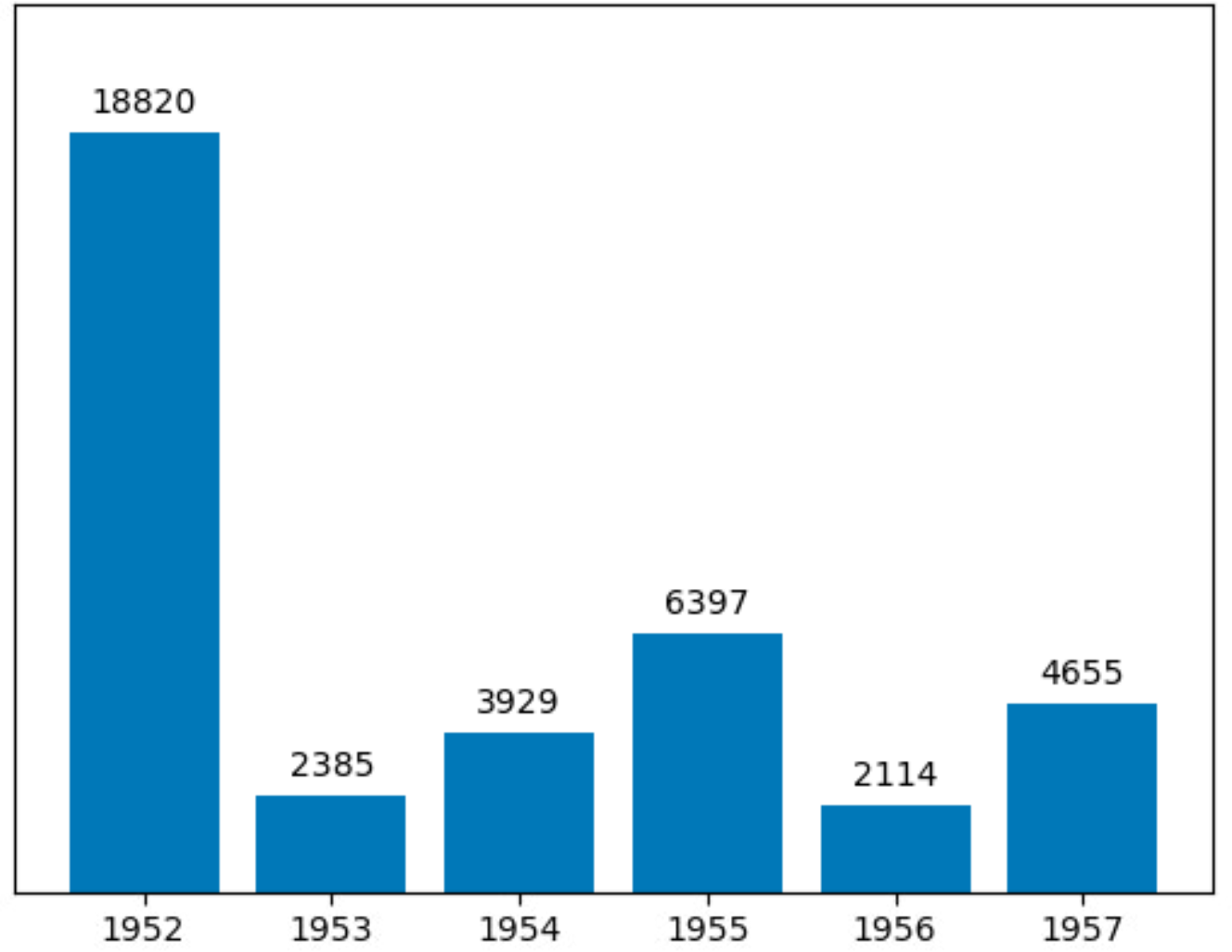

No ano de 1953, o museu publicou oito boletins (números 4 a 11). A partir da observação da seleção de conteúdos publicados, em comparação com as notícias de jornal, é possível perceber algumas prioridades de assuntos. A pauta principal deste ano foi o projeto de lei que tramitou na Câmara dos Deputados para a liberação das verbas para construção da sede própria. A partir de 1954, com a aprovação da doação de verbas pelo poder público, até a mudança para a sede própria, o museu passou a publicar apenas um boletim por ano em versões resumidas e sem a reprodução de notícias de jornais.

\section{Um projeto para o MAM}

A partir desta análise, é possível constatar que o objetivo principal do projeto de instituição do MAM Rio, na década de 1950, foi construir sua sede própria. Articulações políticas foram feitas, e o deputado Jorge Lacerda, ligado à UDN ${ }^{23}$, foi peça importante deste processo e passou a constar no conselho deliberativo a partir de 1956. A prefeitura do Rio de Janeiro, então Distrito Federal, doou o terreno, e a Câmara dos Deputados concedeu a verba de 10 
milhões de cruzeiros para o início da construção da sede própria no Aterro do Flamengo. Estas concessões de verbas públicas caracterizaram o MAM Rio como uma instituição público-privada.

O entendimento sobre a necessidade formativa não deve ser observado como uma estratégia aleatória. A decisão política em torno da liberação de verbas públicas teve oposição de parlamentares avessos ao financiamento do museu em prejuízo dos problemas sociais brasileiros. Um forte debate sobre este assunto foi noticiado na imprensa e reproduzido nos boletins do museu. A argumentação a favor da arte ganhou força ao se anexar à causa o papel educativo. Do ponto de vista conceitual, no projeto do museu, é possível perceber a influência dos princípios da Gestalt, presente nas escolas alemãs, como a Bauhaus ou a Escola de Ulm² ${ }^{24}$ e a importância das artes aplicadas e do design, considerando o momento de forte industrialização do Brasil na época.

O programa educativo do MAM Rio oferecia os seguintes cursos: ateliê livre de pintura para adultos e crianças, com Ivan Serpa; desenho estrutural e composição, com Santa Rosa; composição e análise crítica, com Fayga Ostrower; curso prático e teórico de desenho e pintura, com Décio Vieira; iniciação e orientação, com Zélia Salgado, entre outros. As conferências apresentadas pelo MAM Rio exprimiam o caráter eclético da instituição, tendo como alguns exemplos Mário Pedrosa ( $A$ arte de nosso tempo); Mário Schenberg (Uma fase da pintura de Volpi); Santa Rosa (Portinari); Jean Casseu (L'art moderne est-il um monstre?); Sanson Flexor (L'art abstrait et l'affirmation de l'homme nouveau); entre outras.

A característica de pluralidade e modernidade presente no projeto institucional do MAM Rio pode ser observada a partir do projeto arquitetônico e paisagístico encomendado a Affonso Eduardo Reidy e Roberto Burle Marx. O complexo arquitetônico previa a construção de teatro, biblioteca, cinema, cinemateca, restaurantes, livraria, escola, auditórios, além dos espaços expositivos. A opção por começar a construção da sede própria pelo Bloco Escola sinalizava a prioridade do projeto como um espaço educativo. Ao observarmos o projeto comissionado, nota-se a pouca relevância dada às reservas técnicas em termos da área prevista.

24 Apontamos aqui alguns indícios da influência destas escolas alemãs sobre o MAM Rio: as conferências de Max Bill, em 1953; a visita ao Rio de Janeiro de Walter Gropius, em 1954, e de Mies van der Rohe, em 1957; a exposição da Escola Superior de desenho de Ulm, em 1956. 
A precariedade orçamentária enfrentada pelos museus brasileiros, tanto do ponto de vista da formação de acervos como de sua preservação, é um dado concreto. As dificuldades financeiras impunham o trabalho voluntário aos colaboradores do museu, o que justificava a ausência de quadros técnicos em suas equipes constitutivas. No estatuto de 1948, a lista de diretoria apresentou um quadro técnico dividido por departamentos: pintura, escultura, arquitetura, música, teatro e cinema ${ }^{25}$. A partir de 1952, este critério técnico desapareceu da diretoria do museu. No entanto, a importância das práticas de conservação não era um fator desconhecido.

Em 1955, o Ministério da Educação instaurou uma comissão para verificar as condições de preservação do acervo do MNBA e solicitou a Rodrigo Mello Franco de Andrade ${ }^{26}$ que acompanhasse o processo. O parecer da comissão identificou

Figura 9

Planta do projeto encomendado pelos idealizadores do MAM

Rio. Destaques para: em laranja - área Bloco Escola, primeiro prédio a ser construído; em verde - reserva técnica para quadros instalada junto à administração no segundo piso; em amarelo - reserva técnica para esculturas no subsolo (grifo nosso).

Fonte: wikiarquitectura.com



25 Pintura: Cândido Portinari; Escultura: Bruno Giorgi; Arquitetura: Alcides de Rocha Miranda; Música: Luís Heitor Corrêa de Azevedo; Teatro: Tomás Santa Rosa Junior; Cinema: Roberto Luís Assumpção de Araújo.

26 Rodrigo Mello Franco de Andrade foi um personagem fundamental na instituição do MAM Rio e, junto com Castro Maya, esteve presente nas articulações para este projeto desde meados da década de 1940. Ele fez parte da diretoria do SPHAN desde sua fundação, em 1937, permanecendo trinta anos neste cargo. 
a "falta de condições do museu para a adequada conservação e restauração do acervo" (MACHADO, 2009, p. 94). Um estudo foi realizado para adequação das reservas técnicas e espaços destinados à conservação do acervo de acordo com as regras internacionais da época. Este episódio nos mostra como as práticas de conservação e preservação eram um fator conhecido naquele momento.

Conforme os estatutos e boletins publicados nos primeiros anos de funcionamento do MAM Rio, a conservação, no sentido de preservação, não esteve entre os tópicos da meta de formação do MAM Rio. Este fato pode ser entendido como a falta de centralidade na formação de uma coleção do projeto institucional do museu. Ao observarmos a equipe constitutiva do MAM Rio, o nome de Maria Barreto chama a atenção. Segundo Fernanda Machado Tozzo 27, Barreto constou na lista de conservadores do MNBA desde a década de 1940 (MACHADO, 2009, p. 89). Maria Barreto apareceu na lista de diretoria do MAM Rio de 1948 e constou como conservadora no quadro de 1952. No catálogo publicado pelo MAM Rio, em 1953, seu nome foi substituído por Aloysio Ferreira de Salles no cargo de conservador. Na publicação seguinte, em que aparece a equipe constitutiva do museu em 1956, a figura do conservador desaparece, e Maria Barreto deixa de aparecer em qualquer função. Mario Barata, que fez parte dos quadros do MNBA como conservador, noticia a extinção do cargo em sua coluna no Diário de Notícias.

Um fato concreto que causou estranheza geral foi o da recente extinção do único cargo técnico da diretoria do museu: o de conservador. A seleção feita para o acervo permanente - parcial, fraca e desprovida de qualquer critério - também dificultou a tarefa a que o Museu se propôs a realizar (BARATA,1953, p. 5).

Esta pesquisa não encontrou registros sobre o local de armazenamento do acervo no período em que o museu esteve instalado em sua sede provisória. De acordo com Machado, possivelmente ele ficava guardado em algum lugar nas dependências do Palácio Capanema ou na casa de Niomar Muniz Sodré (MACHADO, 2009, p. 114) ${ }^{28}$, então diretora executiva, ou com colecionadores e entusiastas colaboradores do Museu (MACHADO, 2009, p. 131). É possível observar esta prática de normalização da precariedade como sintoma do caráter personalista na gestão do museu, o que vai permanecer até o incêndio de 1978.

27 Especialista e consultora para conservação e restauração de arte moderna e contemporânea.

28 Segundo depoimento de Heloisa Lustosa à Fernanda Machado, documentos do MAM Rio ainda eram guardados na casa de Niomar Muniz Sobre até a década de 1980, tendo sido perdidos em um outro incêndio que aconteceu em sua residência. 
Na coluna em que Barata mencionava a extinção do cargo de conservador, ele também traçou duras críticas ao que chamou de "joguete de grã-finos" como forma de gestão do museu. Ele enfatizou que um museu deve ter "funções educativas" e "propósitos construtivos", não podendo servir a uma "aventura pessoal" ou "grupo artístico". Neste sentido, podemos observar o problema que envolve a gestão de patrimônio público em uma sociedade patriarcal patrimonialista como a brasileira em que "o predomínio de vontades particulares encontra seu ambiente próprio em círculos fechados e pouco acessíveis a uma ordenação impessoal" (HOLANDA, 1995, p.146).

Em 1958, quando o MAM Rio foi transferido para o Bloco Escola, a exposição de abertura, reunindo parte da coleção permanente, incluiu 63 obras estrangeiras ( 43 pinturas, 7 trabalhos em papel - gravura, guache, aquarela e pastel - e 13 esculturas). O motivo da ausência de artistas brasileiros ${ }^{29}$ na mostra de inauguração da nova sede foi o empréstimo da coleção para a exposição Arte Moderno en Brasil, que teve circulação pela Argentina, Chile e Peru. Entre as atividades valorizadas pela administração do MAM Rio nestes anos iniciais, observou-se a organização de exposições internacionais na América Latina, nos Estados Unidos e na Europa, com o objetivo de divulgar a arte brasileira no exterior. Estas iniciativas aconteciam com o apoio institucional e logístico do Itamaraty.

\section{O MAM Rio e as transformações de seu tempo}

As grandes transformações características do século XX proporcionaram um terreno fértil para o projeto moderno no Brasil. A industrialização gerou um aumento das cidades em um país que deixava de ser predominantemente rural para se tornar urbano. A arquitetura moderna brasileira se beneficiou desta conjuntura e tornou-se referência internacional. O avanço dos meios de comunicação de massa e as migrações decorrentes de duas guerras mundiais são acontecimentos relevantes neste cenário. O desenvolvimento da arte moderna foi inerente a esta conjuntura.

\footnotetext{
29 De acordo com as listas publicadas pelo museu até 1957, a coleção contava com os seguintes artistas brasileiros: Abraham Palatinik, Ahmés de Paula Machado, Alberto da Veiga Guignard, Alfredo Cescihatti, Cândido Portinari, Cícero Dias, Darel Valença Lins, Dea de Campos Lemos, Elisa Martins da Silveira, Emiliano Di Cavalcanti, Enrico Bianco, Fabio Barbosa da Silva, Fayga Ostrower, Felícia Leiner, Firmino Saldanha, Flávio de Carvalho, Heitor dos Prazeres, Henrique Oswald, Inimá J. de Paula, Ione Saldanha, Ismael Nery, Ivan Serpa, Lasar Segall, Lígia Clark, Livio Abramo, Lula Cardoso Ayres, Margaret Spence, Maria Leontina, Maria Martins, Mario Cravo Junior, Oswaldo Goeldi, Pedro Correia de Araujo, Percy Lau, Poty Lazzarotto, Sansão Castello Branco, Sílvia Meyer, Vera Bocayuva Cunha, Yllen Kerr e Zélia Salgado.
} 
Ao observarmos a formação do MAM Rio, é possível entender a opção por instalar o museu em uma sede provisória como parte deste movimento. Neste ambiente de vasta transformação política e social, a arte não deixou de cumprir seu papel. As discussões sobre as múltiplas possibilidades do que seria o moderno estava em pauta, e a institucionalização da arte fazia parte deste processo de mudança. A irregularidade da modernização no Brasil e seu projeto utópico podem ser observados nas contradições expressas na relação entre uma vanguarda artística, a elite - que tomou este projeto moderno para si - e o Estado, que atuou como parceiro financiador desses desejos. Conforme teorizou Sérgio Buarque de Holanda (1995), em seu conceito de "homem cordial", a promiscuidade entre o público e o privado, característica na gestão dos bens coletivos na sociedade brasileira, permanece até hoje como um traço a ser superado.

A escolha institucional de priorizar o projeto educativo em detrimento da formação de um acervo fez parte da ambiguidade da experiência moderna, que teve a tarefa de romper com o passado em direção ao novo, mas que precisava afirmar a tradição para que a cultura se fortalecesse e avançasse. A confirmação desta herança cultural era afirmada ao valorizar o aprendizado e o ensino pautado em conhecimento construído e compartilhado historicamente.

A presença de Maria Martins na gestão dos anos iniciais do MAM Rio e sua colaboração na formação de sua coleção nos mostram o caráter coletivo deste projeto institucional, que contou com a participação de artistas, críticos, jornalistas, intelectuais, arquitetos e políticos, e reforça a ambivalência deste projeto moderno, que, mesmo diante de todos os problemas, contou com a cooperação indispensável deste grupo de agentes para sua realização.

A despeito de a constituição de um acervo não ser o objetivo final no projeto do MAM Rio e de não ter havido uma orientação conceitual clara para a formação da coleção, ela ganhou corpo. De acordo com o levantamento das listas publicadas durante os anos em que o museu funcionou com sede provisória no Palácio Capanema, a coleção atingiu 185 obras. Em 1966, o acervo contava com 299 pinturas, 64 desenhos, 16 colagens, 3 tapeçarias, 2 cerâmicas, 56 esculturas e 232 gravuras, somando 672 obras, contendo artistas fundamentais tais como: Picasso, Klee, Kandinsky, Matisse, Arp, Dali, Miró, Léger, Lhote, Dubuffet, Magritte, Bill, Magnelli, Tanguy, Pollock, Rothko, Rivera, Brancusi, Giacometti, Brauer, entre outros, sem mencionar artistas brasileiros. Entre aquisições e doações de patronos e artistas, a formação de uma coleção foi colateral ao projeto do museu. Mais de $80 \%$ desta coleção se perdeu no terrível incêndio que atingiu o museu em 1978. 
As incertezas sobre a legitimação da arte produzida no presente, na instituição de um museu que não tinha como princípio a conservação de uma arte consagrada pelo tempo, fizeram parte dos desafios de formação dos museus de arte moderna e também do MAM Rio. A defesa de um espaço diferente dos museus tradicionais, que viabilizasse a divulgação da arte moderna - a partir de exposições temporárias, apresentação de novos artistas e tendências, cursos de arte, e formação de plateia - teve como estratégia de realização a opção por privilegiar a construção de uma sede própria. $\mathrm{O}$ projeto arquitetônico e paisagístico de Affonso Eduardo Reidy e Burle Marx simbolizava este projeto civilizatório moderno. A análise deste período inicial de formação do MAM Rio pode auxiliar a pensar sobre as políticas de formação de acervo e sobre a importância das coleções de arte públicas na manutenção dos estudos da arte e na compreensão de nossa história.

\section{Referências}

AQUINO, Flávio de. A Arte no Nosso Tempo. In: MUSEU DE ARTE MODERNA DO RIO DE JANEIRO. Rio de Janeiro: MAM Rio, 1952. (catálogo - exposição permanente). p 7-10.

BAPTISTA, Anna Paola P. Absolutamente modernos. A arte brasileira das Bienais e dos MAMs e os desafios de uma coleção particular. In: COLÓQUIO DO COMITÊ BRASILEIRO DE HISTÓRIA DA ARTE, XXIV, 2004, Belo Horizonte. Anais eletrônicos. Disponível em: http://www.cbha.art.br/coloquios/2004/ anais/anais2004.html Acesso em: 21. Maio 2021.

BARATA, Mário. Modernismo e Pif-Paf. Diário de Notícias, Rio de Janeiro, 1 mar. 1953. Coluna Artes Plásticas, p.5.

BARATA, Mário. Museu de Arte Moderna do Rio de Janeiro. In: MUSEU DE ARTE MODERNA DO RIO DE JANEIRO. Rio de Janeiro: MAM Rio, 1952. (catálogo da exposição). p. 4-14.

BARDI, Lina Bo. Cinco anos entre os "brancos". In: GRINOVER, Marina. RUBINO, Silvana (org). Lina por escrito (textos escolhidos de Lina Bo Bardi). São Paulo: Cosac Naify, 2009. p. 130 - 136.

BENTO, Antônio. A exposição do patrimônio do Museu de Arte Moderna. Diário Carioca, Rio de Janeiro, 17 jan. 1953. In: BOLETIM DO MUSEU DE ARTE MODERNA DO RIO DE JANEIRO. Rio de Janeiro: Museu de Arte Moderna do Rio de Janeiro, n. 5, fev. 1953. p. 14.

BENTO, Antônio. Nota sobre os quadros de Picasso do Museu de Arte Moderna. Diário Carioca, Rio de Janeiro, 15 jan. 1953. In: BOLETIM DO MUSEU DE ARTE MODERNA DO RIO DE JANEIRO. Rio de Janeiro: Museu 
de Arte Moderna do Rio de Janeiro, n. 6, maio 1953. p.16.

BOLETIM DO MUSEU DE ARTE MODERNA DO RIO DE JANEIRO. Rio de Janeiro: MAM Rio, n. 17, jan.1959.

BOLETIM DO MUSEU DE ARTE MODERNA DO RIO DE JANEIRO. Rio de Janeiro: MAM Rio, n. 16, jan.1958.

BOLETIM DO MUSEU DE ARTE MODERNA DO RIO DE JANEIRO. Rio de Janeiro: MAM Rio, n. 15, jan. 1957.

BOLETIM DO MUSEU DE ARTE MODERNA DO RIO DE JANEIRO. Rio de Janeiro: MAM Rio, n. 14, jan.1956.

BOLETIM DO MUSEU DE ARTE MODERNA DO RIO DE JANEIRO. Rio de Janeiro: MAM Rio, n. 13, jan. 1955.

BOLETIM DO MUSEU DE ARTE MODERNA DO RIO DE JANEIRO. Rio de Janeiro: MAM Rio, n. 12, jan. 1954.

BOLETIM DO MUSEU DE ARTE MODERNA DO RIO DE JANEIRO. Rio de Janeiro: MAM Rio, n. 11, set. 1953.

BOLETIM DO MUSEU DE ARTE MODERNA DO RIO DE JANEIRO. Rio de Janeiro: MAM Rio, n. 10, ago. 1953.

BOLETIM DO MUSEU DE ARTE MODERNA DO RIO DE JANEIRO. Rio de Janeiro: MAM Rio, n. 9, jul. 1953.

BOLETIM DO MUSEU DE ARTE MODERNA DO RIO DE JANEIRO. Rio de Janeiro: MAM Rio, n. 8, jun. 1953.

BOLETIM DO MUSEU DE ARTE MODERNA DO RIO DE JANEIRO. Rio de Janeiro: MAM Rio, n. 7, maio 1953.

BOLETIM DO MUSEU DE ARTE MODERNA DO RIO DE JANEIRO. Rio de Janeiro: MAM Rio, n. 6, mar./abr.1953.

BOLETIM DO MUSEU DE ARTE MODERNA DO RIO DE JANEIRO. Rio de Janeiro: MAM Rio, n. 5, fev.1953.

BOLETIM DO MUSEU DE ARTE MODERNA DO RIO DE JANEIRO. Rio de Janeiro: MAM Rio, n. 4, jan. 1953.

BOLETIM DO MUSEU DE ARTE MODERNA DO RIO DE JANEIRO. Rio de Janeiro: MAM Rio, n. 3, dez. 1952.

BOLETIM DO MUSEU DE ARTE MODERNA DO RIO DE JANEIRO. Rio de Janeiro: MAM Rio, n. 2, nov. 1952. 
BOLETIM DO MUSEU DE ARTE MODERNA DO RIO DE JANEIRO. Rio de Janeiro: MAM Rio, n. 1, out. 1952.

CALLADO, Ana Arruda. Maria Martins: uma biografia. Rio de Janeiro: Gryphus, 2004.

ESTATUTO DO MUSEU DE ARTE MODERNA DO RIO DE JANEIRO. Rio de janeiro: MAM Rio,1986.

ESTATUTO DO MUSEU DE ARTE MODERNA DO RIO DE JANEIRO. Rio de janeiro: MAM Rio,1959.

ESTATUTO DO MUSEU DE ARTE MODERNA DO RIO DE JANEIRO. Rio de janeiro: MAM Rio,1953.

ESTATUTO DO MUSEU DE ARTE MODERNA DO RIO DE JANEIRO. Rio de Janeiro, 1948.

HOLANDA, Sérgio Buarque de. Raízes do Brasil. 26 ed. São Paulo: Companhia das Letras, 1995.

INAUGURAÇÃO, Ontem, do Museu de Arte Moderna. Correio da manhã, Rio de Janeiro, p.12, 21 jan. 1949.

MACHADO, Fernanda Tozzo. Os museus de arte no Brasil moderno: os acervos entre a formação e a preservação. Orientador: Marcos Tognon. 2009. Dissertação (Mestrado) Instituto de Filosofia e Ciências Humanas, Universidade Estadual de Campinas, Campinas, 2009.

MARCEL DUCHAMP'S letters to Maria Martins* 1946-1967/68. Disponível em: http://www.golob-gm.si/32-Marcel-Duchamp-s-letters-to-Maria-Martins.htm. Acesso em: 22 jun. 2021.

MARTINS, Maria. Poeira da vida. Correio da Manhã, Rio de Janeiro, p. 5, 12 nov.1967.

MAYA, Castro. [Entrevista concedida a] Yvone Jean. Correio da Manhã, Rio de Janeiro, p. 1, 12 ago. 1951.

MUSEU DE ARTE MODERNA DO RIO DE JANEIRO. Patrimônio do MAM. Rio de Janeiro: MAM RIO, ago.1966. (catálogo da exposição).

MUSEU DE ARTE MODERNA DO RIO DE JANEIRO. Museu de Arte Moderna do Rio de Janeiro. Rio de Janeiro: MAM Rio, 1958. (catálogo - exposição permanente).

MUSEU DE ARTE MODERNA DO RIO DE JANEIRO. Museu de Arte Moderna 
do Rio de Janeiro. Rio de Janeiro: MAM Rio, 1957. (catálogo n. ${ }^{\circ} 4$ - exposição permanente).

MUSEU DE ARTE MODERNA DO RIO DE JANEIRO. Museu de Arte Moderna do Rio de Janeiro. Rio de Janeiro: MAM Rio, 1956. (catálogo n. ${ }^{\circ} 3$ - exposição permanente).

MUSEU DE ARTE MODERNA DO RIO DE JANEIRO. Museu de Arte Moderna do Rio de Janeiro. Rio de Janeiro: MAM Rio, 1954. (catálogo n. ${ }^{\circ} 2$ - exposição permanente).

MUSEU DE ARTE MODERNA DO RIO DE JANEIRO. Museu de Arte Moderna do Rio de Janeiro. Rio de Janeiro: MAM Rio, 1952. (catálogo da exposição).

MUSEU DE ARTE MODERNA DO RIO DE JANEIRO. Museu de Arte Moderna do Rio de Janeiro. Rio de Janeiro: MAM Rio, 1952. (catálogo - exposição permanente).

PARADA, M. B. A. A Fundação do Museu de Arte Moderna do Rio de Janeiro: a elite carioca e as imagens da modernidade no Brasil dos anos 50. 1993. Dissertação (Mestrado) - Pontifícia Universidade Católica do Rio de Janeiro, Rio de Janeiro, 1993.

PEDROSA, Mário. A Coleção do Museu de Arte Moderna. Tribuna da Imprensa, Rio de Janeiro, 17 jan. 1953. In: BOLETIM DO MUSEU DE ARTE MODERNA DO RIO DE JANEIRO. Rio de Janeiro: Museu de Arte Moderna do Rio de Janeiro, n. 5, fev. 1953, p. 13.

REIDY, Alfonso Eduardo. Plantas do Museu de Arte Moderna do Rio de Janeiro. Disponível em: https://pt.wikiarquitectura.com/constru\%C3\%A7\%C3\%A3o/ museu-de-arte-moderno-do-rio-de-janeiro/ Acesso em: 7 jun. 2021.

RESENDE, Maria Beatriz et. al. Verbete Serviço do Patrimônio Histórico e Artístico Nacional (SPHAN) 1937-1946. Disponível em: http://portal.iphan. gov.br/dicionarioPatrimonioCultural/detalhes/61/servico-do-patrimonio-historico-e-artistico-nacional-sphan-1937-1946. Acesso em: 7 de jun. 2021.

SANT'ANNA, Sabrina M. P. Pretérito do futuro: o Museu de Arte Moderna do Rio de Janeiro e seu projeto de modernidade. In: Revista de Ciências Sociais, v. $41, n^{\circ} 1$, p. $67-86,2010$

SCHWARCZ, Lilian Moritz. Brasil: uma biografia. São Paulo: Companhia das letras, 2015.

SIQUEIRA, Vera Beatriz Cordeiro. A riqueza pelas coisas: a coleção Raymundo Ottoni Castro Maya. 1999. Tese (Doutorado em História Social) - Instituto de Filosofia e Ciências Sociais, Universidade Federal do Rio de Janeiro, Rio de Janeiro, 1999. 
WOLF, Justin. The Betty Parsons Gallery. Disponível em: https://www.theartstory.org/gallery-betty-parsons.htm. Acesso em: 22 jun. 2021.

WOLF, Justin. The Sidney Janis Gallery. Disponível em: https://www.theartstory.org/gallery-janis-sidney.htm. Acesso em: 22 jun. 2021.

ZANINI, Walter. O belo esforço do Rio. O Tempo, São Paulo, 22 jan.1953. In: BOLETIM DO MUSEU DE ARTE MODERNA DO RIO DE JANEIRO. Rio de Janeiro: MAM Rio, n. 6, mar./abr. 1953. p 10. 